\title{
PROFIL MUTU KOMODITI UNGGULAN PERKEBUNAN KABUPATEN ENDE (KOMODITI KAKAO)
}

\author{
Emilia S.A. Wangge \\ Fakultas Pertanian-Universitas Flores \\ Emilia_wangge@yahoo.co,id
}

\begin{abstract}
The study of quality profile of plantation excellent commodity in Ende Regency (hazelnut commodity) is to provide information about the degree composition of water and fat on hazelnut commodity in Ende Regency. Hazelnut commodity profile benefits for the provision of trade opportunity information and the investment of hazelnut cultivation to both foreign and domestic investors, as well as business persons, in order to boost the investment growth in Ende Regency. This study was conducted in the Agriculture Technology Laboratory of Udayana University of Denpasar. The presentation of hazelnut commodity profile in EndeRegency of East Nusa Tenggara Province apparently reveals that this region has great potential to be further developed viewed from quality content aspect.
\end{abstract}

Keywords: Fat degree, water degree, Hazelnut.

\section{PENDAHULUAN}

Salah satu komoditi andalan sektor perkebunan kabupaten Ende di Indonesia adalah kakao. Komoditi kakao memiliki peranan yang cukup penting bagi perekonomian nasional, khususnya sebagai penyedia lapangan kerja, sumber pendapatan dan devisa negara. Komoditi kakao juga berperan mendorong pengembangan wilayah dan pengembangan agroindustri. Sampai tahun 2009, perkebunan kakao telah menyediakan lapangan kerja dan sumber pendapatan bagi sekitar 1.526.271 kepala keluarga petani., yang sebagian besar berada di kawasan timur Indonesia (KTI) serta memberikan sumbangan devisa terbesar ketiga sub sektor perkebunan setelah karet dan minyak sawit dengan nilai produksi sebesar 795.581 ton.

Perkebunan kakao di Indonesia mengalami perkembangan pesat dalam kurun waktu 20 tahun terakhir. Sampai tahun 2012, Indonesia memiliki lahan perkebunan kakao seluas 1,5-1,6 juta 
Emilia: Profil komoditi unggulan perkebunan Kabupaten Ende (komoditi kakao)

hektare. Berdasarkan data Kementrian Pertanian, dari angka itu sebanyak $65 \%$ diantaranya berlokasi di sulawesi dan $15 \%$ di Sumatra. Sedangkan sisanya di Jawa, Bali,kalimantan, Maluku, Papua, serta Nusa Tenggara Timur.perekbunan Kakao tersebut sebagian besar $(87,3 \%)$ dikelola oleh rakyat dan selebihnya 6,0\% dikelola perekebunan besar negara serta $6,7 \%$ perkebunan swasta. Jenis tanaman kakao yang diusahakan jenis kakao lindak dengan sentra produksi utama adalah Sulawesi selatan, Sulawesi tenggara, dan sulawesi tengah. Disampinh itu juga diusahakan jenis kakao mulia oleh perkebunan besar negara di jawa Timur dan Jawa tengah. Sedangkan di NTT, Khusunya di daratan NTT , khususnya daratan Flores, jenis kakao yang dikembangkan bervariasi antara jenis Lindak dari Sulawesi dan jenis mulia dari Pulau Jawa.

Pada dasarnya kakao di Flores, khususnya di Ende tidak kalah mutunya dengan kakao yang dunia,terutama dalam aspek kualitas,bahkan bila ditlakukan fermentasi yang baik dapat mencapai cta rasa setara dengan kakao yang berasal dari Ghana. Selain itu kakao dari Flores-Ende mempunyai kelebihan yaitu tidak mudah meleleh sehingga cocok bila dipakai untuk belnding. Dengan keunggulan tersebut,kakao Ende memiliki peluang pasar yang cukup besar, baik untuk pasar, domestik maupun pasar ekspor. Artinya, peluang untuk mu pendorong pertumbuhan dan distribusi pendapatan masih sangat cukup terbuka.

Peningkatan produksi kakao yang tinggi di Ende juga diikuti dengan peningkatan pendapatan petani yang cukup signifikan.Hal ini disebabkan oleh kenaikan harga kakao karena adanya peningkatan kualitas kakao. Situasi ini juga berimbas pada meningkatnya posisi tawar (bergaining position0 petani terutama karena proses pengolahan kakao telah melalui proses fermentasi yang baik.

Kakao diproduksi di semua wilayah yang berada di kabupaten ografpaten Ende mencapai 2851 ton dan pada tahun 2007 meningkat menjadi 2946 ton dengan rata-rata produktivitas $942 \mathrm{~kg} / \mathrm{ha}$.Perkembangan produksi kakao di kabupaten Ende selama 6 tahun terakhir dapat dilihat pada tabel berikut : 
Emilia: Profil komoditi unggulan perkebunan Kabupaten Ende (komoditi kakao)

Tabel 1. Produksi kakao di kabupaten Ende dari tahun 2006 s/d 2011

\begin{tabular}{|c|l|l|l|}
\hline Tahun & Luas Areal & Produksi & Produktivitas \\
\hline & (ha) & (ton) & (kg/ha) \\
\hline 2006 & 5376,8 & 2851 & 942 \\
\hline 2007 & 5504,3 & 2946 & 993 \\
\hline 2008 & 5475,5 & 3357,9 & 989,5 \\
\hline 2009 & 5441,7 & 3339,1 & 1000,98 \\
\hline 2010 & 5504,8 & 3439,2 & 995,57 \\
\hline 2011 & 5889 & 3196,7 & 906 \\
\hline
\end{tabular}

Pada Tabel 1.1 tersebut nampak bahwa produksi kakao di kabuppaten ende cukup fluktuatif dari tahun ke tahun.Pada tahun 2011 produksi kakao di kabupaten Ende mencapai 3431,21 ton atau naik sekitar 21,59\% sejak tahun 2006. Sebaliknya proses pengolahan biji kakao masih sangat terbatas dengan peralatan seadanya sehingga harga kakao pun mengalami fluktuasi mulai dari level Rp.15.000, dan meningkat sampai paada level Rp.22000,seiring dengan semakin berkembangnya informasi pengolahan kakao.

\section{Tujuan}

Penyusunan profil komoditi kakao ini dimaksudkan untuk memberikan informasi tentang Komposisi kandungan kadar air dan lemak pada komoditi kakao di Kabupaten Ende. Profil komoditi kakao berguna sebagai Informasi peluang usaha dan investasi usaha budidaya komoditi kakao kepada investor baik luar maupun dalam negeri serta kalangan dunia usaha, sehingga dapat memacu pertumbuhan investasi di Kabupaten Ende.

\section{METODE PENELITIAN}

Penelitian ini dilaksanakan di Laboratorium Analisis Pangan Fakultas Teknologi Pangan Universitas Udayana, Denpasar. Penelitian ini dilaksanankan pada bulan April 2013. Alat-alat yang digunakan dalam penelitian ini diantaranya kertas saring Whatman (40 mesh), alat distilasi Soxhlet, tabung ekstraksi soxhlet, mortar, timbangan,botol tombangan, penangas air,oven, tabung reaksi,mikrotube,kapas dan tisu.Bahan yang digunakan dalam penelitian ini adalah kakao berasal dari beberapa desa yang ada di Kabupaten Ende.Prosedur manganalisa kadar air dapat dilihat pada diagram alir berikut ini : 
Emilia: Profil komoditi unggulan perkebunan Kabupaten Ende (komoditi kakao)

\section{HASIL DAN PEMBAHASAN}

Tabel 1. Kadar air dan Kadar Lemak Pada Kopra Yang Dihasilkan beberapa desa di Kabupaten Ende.

\begin{tabular}{lccl}
\hline \multicolumn{1}{c}{ Nama Desa } & Kadar Air $(\%)$ & Kadar Lemak $(\% \mathrm{bk})$ & \multicolumn{1}{c}{ Keterangan } \\
\hline Desa Tou Barat & 2,15 & 50,63 & Syarat: \\
Desa Tou Barat & 3,79 & 45,73 & Kadar Air : 2,1\% \\
Desa Rangalaka & 2,29 & 51,73 & Kadar Lemak: 54,7\% \\
Desa Rangalaka & 3,77 & 46,14 & Kadar Air : 3,65\% \\
Desa Ndondo & 2,14 & 51,76 & Kadar Lemak: 53,05\% \\
Desa Ndondo & 3,57 & 46,11 & Sumber : Data Primer, hasil \\
Desa Liabeke & 2,02 & 50,63 & \\
Desa Liabeke & 2,13 & 51,12 & \\
Desa Woloara & 2,10 & 51,31 & \\
Desa Woloara & 3,37 & 46,01 & \\
Desa Wolosambi & 3,46 & 49,76 & \\
Desa Wolosambi & 2,22 & 51,42 & \\
Desa Wolosoko & 3,70 & 48,78 & \\
Desa Wolosoko & 2,12 & 52,28 & \\
Desa Nualise & 3,53 & 49,68 & \\
Desa Nualise & 2,13 & 51,24 & \\
Desa Lisedetu & 3,51 & 44,69 & \\
Desa Lisedetu & 2,30 & 53,03 & \\
Desa Ondorea Barat & 2,12 & 53,48 & \\
Desa Ondorea Barat & 3,38 & 46,68 & \\
Desa Bhera mari & 3,47 & 48,27 & \\
Desa Bheramari & 2,01 & 52,91 & \\
Desa Tiwurea & 2,10 & & \\
\hline
\end{tabular}

Berdasarkan hasil analisa, kadar lemak dan kadar air yang terkandung dalam biji kakao kering (Thebroma cacao L.), kadar lemak tertinggi sebesar 53,48 \% berasal dari desa Ondorea barat, sedangkan kadar lemak terendah sebesar $44,69 \%$ berasal dari desa Lisedetu. Untuk lebih jelasnya dapat dilihat pada table 1.Biji kakao yang digunakan sebagai bahan baku pada industri pengolahan makanan memiliki berbagai kandungan senyawa yang penting bagi tubuh, kandungan lemak pada kakao sangat tinggi dibandingkan dengan kandungan senyawa lainnya. Biji kakao Ende memiliki kadar air berkisar 2,02\% sampai $3,70 \%$. Standar Nasional Indonesia menetapkan mutu biji kakao Indonesia sebesar 7,5\%. Adapun syarat mutu biji kakao dapat dilihat pada Tabel 
Emilia: Profil komoditi unggulan perkebunan Kabupaten Ende (komoditi kakao)

Tabel 2. Persyaratan Umum Biji Kakao

\begin{tabular}{clccc}
\hline No. & \multicolumn{1}{c}{ Karakteristik } & Mutu I & Mutu II & Mutu III \\
\hline 1 & Jumlah biji/100 g & $\leq 85$ & $\leq 100$ & $\geq 120$ \\
2 & Kadar air, \% (b/b) maks & 7,5 & 7,5 & $>7,5$ \\
3 & Berjamur, \% (b/b) maks & 3 & 4 & $>4$ \\
4 & Tak Terfermentasi \%(b/b) maks & 3 & 8 & $>8$ \\
5 & Berserangga, hampa, & 3 & 6 & $>6$ \\
& berkecambah \% (b/b) maks & & & \\
6 & Biji pecah, \% (b/b) maks & 3 & 3 & 3 \\
7 & Benda asing \% (b/b) maks & 0 & 0 & 0 \\
8 & Kemasan kg, netto/karung & 62,5 & 62,5 & 62,5 \\
\hline & Sumber : SNI 2323-2000 & & &
\end{tabular}

Proses pengolahan kakao

karakteristik fisik dan pencemaran atau menjadi biji kakao kering meliputi : tingkat kebersihan. Karakter fisik pemetikan, pemeraman, sortasi, merupakan persyaratan paling utama fermentasi, pencucian, pengeringan, karena menyangkut rendemen lemak pengemasan dan penggudangan. Bagian yang berguna dalam pengolahan buah kakao segar menjadi biji kering adalah pulp dan biji basah, sedangkan plasenta serta kulit buahnya dibuang (Mulato dan Widyatomo, 2003).

Mutu biji kakao sangat dipengaruhi oleh beberapa faktor pra panen, seperti genetis tanaman, lingkungan fisik, dan praktek budidaya, serta penanganan pasca panen seperti pemanenan, fermentasi, pencucian, pengeringan dan pengangkutan (Putra dan Wartini, 1998). diperoleh kadar air $2,02 \%$ sampai $3,70 \%$.

Persyaratan mutu yang diatur dalam syarat perdagangan meliputi dan diukur dengan tata cara dan peralatan baku yang disepakati oleh institusi internasional. Wahyudi et al., (2008) menyatakan kualitas kakao diuji dengan berbagai pengujian laboratorium maupun organoleptik yang meliputi kadar air, ukuran biji dan keseragaman, kadar kulit biji, kadar lemak, organoleptik dan keasaman.

1. Kadar air

Kadar air merupakan sifat fisik yang sangat penting dan sangat diperhatikan,karena selain sangat berpengaruh terhadap rendemen hasil, kadar air berpengaruh pada daya tahan biji kakao terhadap kerusakan, terutama saat 
Emilia: Profil komoditi unggulan perkebunan Kabupaten Ende (komoditi kakao)

penggudangan dan pengangkutan.

Biji kakao yang mempunyai kadar air tinggi sangat rentan terhadap serangan jamur dan serangga dan cenderung menimbulkan kerusakan citrasa dan aroma dasar yang tidak dapat diperbaiki pada proses berikutnya. Kelembaban ruang simpan yang melebihi kelembaban seimbang akan menyebabkan kenaikan kadar air dan bila kadar air mencapai lebih dari 7,5\% memberi peluang bagi jamur dan hama untuk tumbuh dan berkembang (Wahyudi dan Sulistyowati, 1988). Standar kadar air biji kakao mutu ekspor adalah 7,5\%. Jika lebih tinggi dari nilai tersebut, biji kakao tidak aman disimpan dalam waktu lama, sedang jika kadar air terlalu rendah biji kakao cenderung menjadi rapuh.

2. Ukuran biji dan keseragaman

Seperti halnya kadar air, ukuran biji kakao sangat menentukan rendemen hasil lemak. Makin besar ukuran biji kakao, makin tinggi rendemen lemak dari dalam biji. Ukuran biji kakao dinyatakan dalam jumlah biji (beans account) per $100 \mathrm{~g}$ contoh uji yang diambil secara acak pada kadar air $7,5 \%$. Ukuran biji rata-rata yang masuk kualitas ekspor adalah antara
$1,0-1,2 \mathrm{~g}$ atau setara dengan $85-100$ biji per $100 \mathrm{~g}$ contoh uji. Ukuran biji kakao kering sangat dipengaruhi oleh jenis tanaman, kondisi kebun (curah hujan) selama perkembangan buah, perlakuan agronomis dan cara pengolahan (Mulato dan Widyatomo, 2003).

\section{Kadar kulit biji}

Kulit biji biji kakao ditentukan oleh jenis tanaman dan cara pengolahan. Biji kakao yang tidak difermentasi memiliki kadar kulit yang lebih tinggi karena adanya pulp yang menempel pada kulit ari. Biji kakao yang dicuci kadar kulitnya berkurang menjadi 8-10\%, akan tetapi menjadi lebih rapuh sehingga kurang toleran terhadap serangan jamur atau serangga.

Kadar kulit yang diinginkan adalah yang paling minim yaitu sekitar $11 \%$ karena cukup kuat untuk melindungi biji dari kondisi lingkungan yang kurang menguntungkan seperti serangan hama dan jamur. Kulit biji harus bebas dari bahan lain yang melekat seperti pulp kering karena dapat mencemari nib yang dipisahkan dari kulit (Wahyudi et al., 2008). 
Emilia: Profil komoditi unggulan perkebunan Kabupaten Ende (komoditi kakao)

4. Kadar lemak

Kadar lemak pada umumnya dinyatakan dalam persen dari berat kering

keping biji. Selain oleh bahan tanam dan musim, kandungan lemak dipengaruhi oleh perlakuan pengolahan, dan jenis bahan tanaman. Biji kakao yang berasal dari pembuahan musim hujan umumya mempunyai kadar lemak lebih tinggi (Mulato dan Widyatomo, 2003). Lebih lanjut dikatakan bahwa, karakter fisik biji kakao pasca pengolahan, seperti kadar air, tingkat fermentasi dan kadar kulit, berpengaruh pada rendemen lemak biji kakao. Kisaran kadar lemak biji kakao Indonesia adalah antara 49 $52 \%$.Lebih dari $70 \%$ darigliseridaterdiridaritiga senyawa tidak jenuh tunggal yaitu oleodipalmitin (POP), oleodistearin (SOS) dan oleopalmistearin (POS). Keberadaan asam lemak bebas di dalam lemak kakao harus dihindari karena hal itu merupakan salah satu indikator kerusakan mutu. Asam lemak bebas umumnya muncul jika biji kakao kering disimpan di gudang yang kurang bersih dan lembab.
5. Organoleptik

Citarasa dan aroma khas cokelat akan berkembang lebih sempurna pada biji kakao yang telah mengalami proses fermentasi yang sempurna. Secara kualitatif, kesempurnaan proses fermentasi dapat dilihat dari perubahan warna keping biji kakao. Dengan uji belah dapat diketahui bahwa warna dominan keping biji tanpa fermentasi keabu-abuan sering disebut biji slaty. Warna tersebut secara bertahap akan berubah menjadi coklat sejalan dengan perkembangan proses dan waktu fermentasi. Makin panjang waktu fermentasi, warna coklat makin dominan. Secara kuantitatif, tingkat kesempurnaan fermentasi dapat dianalisis dengan metoda kimiawi. Penentuan derajat fermentasi berdasarkan warna dilakukan dengan uji belah. Biji kakao dibelah tepat di bagian tengah, arah memanjang dari keping biji. Permukaan biji yang terbelah dapat dilihat dengan jelas. Selain itu, uji ini dapat digunakan untuk menentukan serangan jamur atau serangga di dalam keping biji yang dilihat dari miselia yang tumbuh di dalam keping biji atau telur dan larva 
Emilia: Profil komoditi unggulan perkebunan Kabupaten Ende (komoditi kakao)

serangga yang bersarang di dalam keping biji.

6. Keasaman

Semua biji kakao itu mengandung asam-asam volatil dan non volatil. Diantara jenis asam yang paling dominan adalah asam asetat, asam sitrat dan asam laktat. Asam sitrat berkisar antara 1-2 \% dan separuhnya hilang bersama aliran cairan fermentasi dan dimetabolisasi, sehingga yang tertinggal pada biji kering adalah 0,5 \%. Asam asetat dan asam laktat terbentuk selama fermentasi, dan masuk ke dalam kotiledon / nib. Jumlah asam laktat dan asam asetat pada biji kering bervariasi menurut metode fermentasi, pengeringan, varietas dan asal daerahnya.

Berdasarkan hasil pengamatan di lapangan proses penanganan pasca panen yang dilakukan oleh petani adalah sebagai berikut :

\section{Pemetikan buah}

Pemetikan buah dilakukan dengan memilih buah yang telah masak yakni buah yang sudah berumur 3 sampai 4 bulan.

\section{Sortasi}

Sortasi buah merupakan salah satu tahapan yang penting untuk menghasilkan biji kakao bermutu baik. Sortasi buah ditujukan untuk memisahkan buah kakao yang sehat dari buah yang rusak terkena penyakit, busuk atau cacat.

\section{Pengupasan buah}

Pengupasan buah dilakukan dengan pemecahan buah dengan tujuan untuk mengeluarkan dan memisahkan biji kakao dari kulit buah dan plasentanya. Pengupasan harus dilakukan dengan hati-hati, agar buah tersebut tidak terpotong atau terbelah oleh alat pemotong manual. Biji kakao yang terluka mudah terinfeksi oleh jamur (Puslit Kopi dan Kakao, 2006).

4.Fermentasi

Fermentasi merupakan inti dari proses pengolahan biji kakao. Proses ini tidak hanya bertujuan untuk membebaskan biji kakao dari pulp dan mematikan biji, namun juga untuk memperbaiki dan membentuk cita rasa coklat yang enak dan menyenangkan serta mengurangi rasa sepat dan pahit pada biji (Nasution,1996).Berdasarkan hasil pengamatan di lapangan, petani kabupaten Ende dalam penanganan pasca panen biji kakao ada yang melakukan proses fermentasi dan ada pula yang tidak. Biji kakao yang tidak dilakukan fermentasi, oleh petani 
Emilia: Profil komoditi unggulan perkebunan Kabupaten Ende (komoditi kakao)

setelah dikeluarkan pengupasan langsung dikeringkan dengan cara dijemur di terik matahari. Proses fermentasi yang dilakukan oleh petani kabupaten Ende ada beberapa macam yaitu dengan menggunakan karung sebagai wadah fermentasi selama 3 sampai 5 hari. Selain itu, proses fermentasi yang dilakukan oleh beberapa pengusaha adalah dengan menggunakan peti fermentasi. Peti fermentasi diberi lubang-lubang dengan tujuan untuk aerasi (mengeluarkan cairan) dan menjaga sirkulasi udara di dalam peti. Hal ini dimaksudkan agar biji kakao tersebut tidak terserang jamur/kapang.

\section{Pengeringan}

Pengeringan bertujuan untuk menguapkan air yang masih tertinggal di dalanm biji pasca fermentasi yang semula 50\%-55\% menjadi $7 \%$ agar biji kakao aman disimpan sebelum dipasarkan ke konsumen. Pengeringan biji kakao umumnya dilakukan dengan tiga cara, yaitu cara penjemuran,mekanis dan kombinasi (Ong, 1997).Pengeringan biji kakao yang dilakukan oleh petani kabupaten Ende dengan menjemur biji kakao langsung dibawah sinar matahari dengan menggunakan lantai,terpal ataupun karung sebagai wadah. Lamanya pengeringan berkisar antara 3 sampai 5 hari.

6.Pengemasan dan penggudangan

Pengemasan dilakukan dengan menggunakan karung bersih dan ditempatkan di dalam gudang. Adapun gudang penyimpan yang digunakan adalah gudang yang bersih dan memiliki sirkulasi udara yang baik. Selama biji kakao disimpan dilakukan proses penjemuran,hal ini bertujuan untuk menghindari biji kakao dari serangan kapang.

\section{Kesimpulan}

Berdasarkan pemaparan tentang profil komoditi kakao di Kabupaten Ende Propinsi Nusa Tenggara Timur, nampak jelas bahwa daerah ini memiliki potensi yang besar untuk dikembangkan, dilihat dari aspek kandungan mutu.

Potensi daerah yang besar akan budidaya kakao, perlu didukung dengan aspek legalitas. Berdasarkan UU yang berlaku secara nasional, maka pemerintah daerah dapat membuat peraturan daerah (perda) untuk perijinan, khususnya yang berhubungan dengan perijinan di sektor perkebunan, disamping perlunya melengkapi sertifikasi hak milik atas tanah, agar pembayaran pajak bisa ditertibkan. 


\section{UCAPAN TERIMA KASIH}

Pada kesempatan ini penulis ingin mengucapkan terima kasih kepada semua pihak yang telah membantu dengan caranya masing-masing dalam melengkapi tulisan ini.

\section{DAFTAR PUSTAKA}

Anonim. 2007. Discussion paper on ochratoxin A in cocoa. Codex Alimentarius Commission, Codex Committee on Food Additives and Contaminants, First session. Beijing, China (16-20 April 2007, CX/CF07/1/19).

Ardhana, M.M. dan Fleet, G. H. 2003. The microbial ecology of cocoa bean fermentations in Indonesia. International J. Food Microbiology 86: 87-99.

Aroyeun, S.O. dan Adegoke G.O. 2007. Reduction of ochratoxin A (OTA) in spiked cocoa powder and beverage using aqueous extracts and essential oils of Aframomum danielli. Afr. J. Biotechnol. 6:612616.

Badan Pengawasan Obat dan Makanan. 2004. Status regulasi cemaran dalam produk pangan. Buletin Keamanan Pangan, 6 : 4-5.

Badrun, M. 1991. Program Pengembangan Kakao di Indonesia.Prosiding Komperensi Nasional Kakao III, Medan. Buku 2 : 1-9.

Batista, L.R., S.M. Chalfoun, G. Prado, R.F. Schwan, dan A. E. Wheals. 2003. Toxigenic fungi with processed (green) coffee beans (coffee arabica L.) International J. Food Microbiology. 85(3): 293300.

Betina, V. 1989.Mycotoxins, Chemical, Biological and Environmental
Aspects.Elsevier, AmsterdamOxford-New York-Tokyo.

Bhat, R.V. and J.D. Miller. 2001. Mycotoxin and Food Supply. National Institute of Nutrition, hyderebad, India. 1-10.

Bisbal, F., J.V. Gil, P.V. Martinez.R. Daniel. 2009. ITS -RFLP characterization of black Aspergillus isolates responsible for ochratoxin A contamination in cocoa beans. Eur Food Re Technol. 229:751-755.

Breuer, A. 2005. About Mold. www.ronstate.cdu/ehs/Mold.htm

Bucheli.P., I. Meyer, A. Pittet, G. Vuataz, and R.Viani. 1998. Industrial Storage of Green Robusta Coffee under Tropical Condition and Its Impact on Raw Material Quality and Ochratoxin A Content. J Agric Food Chem. (46):4507 4511.

Buckle, K.A., R.A. Edwards, G.H Fleet dan M.Wooton. 1987. Ilmu Pangan. Penerjemah H. Purnomo dan Adiono. Penerbit Universitas Indonesia.Jakarta.

Carry, J.W., M.A. Klich, and S.B. Beltz. 2005. Characterization of aflatoxin-producing fungi outside of Aspergillus section Flavi. Mycologia 97 (2); 425-432.

Cole, R.J. dan J.W. Dorner. 1999. Biological Control of Aflatoxin and Cyclopiazonic Acid of Peanuts. Proceeding of InternationalSymposium of Mycotoxicology' 99.Chiba-Japan. pp. $70-73$ 